\title{
MACHINE LEARNING BASED MODELLING FOR ESTIMATION OF THE FUNDAMENTAL TIME PERIOD OF PRECAST CONCRETE STRUCTURES USING COMPUTER PROGRAMMING
}

\author{
Nitin Dahiya, Babita Saini and H.D. Chalak
}

\begin{abstract}
Dept. of Civil Engineering, National Institute of Technology Kurukshetra, Haryana, India;nitindahiya17@gmail.com ; bsaini@nitkkr.ac.in; chalakhd@nitkkr.ac.in
\end{abstract}

\begin{abstract}
This research investigated the capability of machine learning approaches using computer programming to evaluate the fundamental time period $\left(\mathrm{F}_{\mathrm{TP}}\right)$ of precast concrete structures. A data set consisting of 288 models with configuration including shear wall and beam-column frame were used in the present study. The 288 models were analysed using Etabs software and Rstudio. Input parameters for the present study consisted of the height of the building, number of bays, length and breadth of the building, cracked or uncracked section, number of storeys and frame type on the $\mathrm{F}_{\mathrm{TP}}$ of precast concrete structures. Out of the 288 models, 108 arbitrary selected models were used for testing and the remaining 180 models were used for training. Linear (LRF), polynomial (PLF) and radial basis (RBF) kernel functions were used for machine learning approach i.e support vector machines (SVM) and gaussian process (GPR). A correlation coefficient of 0.9832 was achieved by linear function-based support vector machines (SVM-LRF) as compared to 0.9284 by gaussian process regression, indicating that SVM-LRF has improved efficiency in predicting the $\mathrm{F}_{\mathrm{TP}}$. The accuracy of the machine learning approaches was verified through comparison with the available equations to evaluate the $\mathrm{F}_{\mathrm{TP}}$ in literature.
\end{abstract}

\section{KEYWORDS}

Fundamental time period, Precast concrete, Machine learning, Support vector machines, Gaussian process

\section{INTRODUCTION}

A pre-cast concrete structure is a complex assembly of the shear wall, beams, column, slab, vertical and horizontal connections. The $F_{T P}$ is a crucial variable for the analysis of precast concrete structures. The majority of proposal available in the literature are based on codal equations which do not take into consideration the cracking of members, storey height variation and material property. This leads to a change in the $F_{T P}$ of a building.

Apart from the height, the two-elements on which the $F_{T P}$ of precast concrete structures rely on are the distribution of mass and stiffness. Thus, any component with rigidity/mass or perhaps both has an impact on the $F_{T P}$ of a pre-cast concrete structure. Mostly due to earthquake amplitude and location of dynamic forces there is a considerable variability with respect to time that causing significant inertia effects on buildings. Under the dynamic characteristics of a building, a building behaves under the influence of dynamic forces which is controlled by its mass and stiffness properties. Furthermore, the sturdiness along with deformability of constituent members are the factors affecting the performance of a building. 


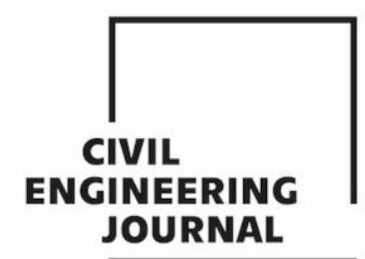

Article no. 41

THE CIVIL ENGINEERING JOURNAL 2-2021

With ever-evolving technology and with high-speed precision computers, the $F_{T P}$ of the structure can be analysed either by an exact eigenvalue analysis or by a logical approach. However, during an earthquake, the codal guidelines offer imperial equation based on the inspection of the $F_{T P}$ of original structures. However, the codal equation is used to determine the dissimilarities in the $F_{T P}$ of structures. Codes and research work provide various formulae and results. In many cases, the analytical approaches and formulae depend on one parameter, i.e height of the building. Probably the most typical expression for the computation of the $F_{T P}$ is [2]:

$$
T=C_{t} \cdot h^{3 / 4}
$$

where, $\mathrm{h}$ is the height and $C_{t}$ is the coefficient, which is determined by the typology of a structure. Equation 1 was first adopted in 1978 by the ATC [2] for RC frames. The $C_{t}$ coefficient was determined based on the measurement of the fundamental time period during the San Fernando earthquake (1971). A regression analysis of the data gives a $C_{t}$ value of 0.075 . IS 1893[20], Eurocode 8[14] and UBC [28] adopt a similar expression assigning the different value of $C_{t}$.

The UBC proposed formulation has been updated in FEMA-450 [17] based on the research carried out by Goel and Chopra [18]. On the basis of the data presented by Goel and Chopra [18], FEMA proposed an expression:

$$
T=C_{r} H_{n}^{x}
$$

where $H_{n}$ is the height, $C_{r}$ is 0.0466 and $\mathrm{x}$ is 0.9 .

Numerous investigators have suggested expression for $F_{T P}$ of $\mathrm{RC}$ frame structures based on the height of the structure (Table 1). Crowley and Pinho [11] proposed an equation for the fundamental time period based on displacement design. Various old buildings were analysed in accordance with previous codes. Crowley and Pinho [12] in 2006 studied the elastic period of various $\mathrm{RC}$ frame building and proposed a simplified expression for the fundamental time period using eigenvalue analysis. The analytical results depicted that the presence of shear walls and partition walls reduces the fundamental time period of a building. Guler et al. [19] proposed an equation for the fundamental period of vibration derived from elastic numerical analysis. Asteris et al. [3] in 2015 studied the parameters affecting the fundamental period of frame structures that include the numbers of span, infill wall panels, location of soft storey and soil structure interaction. Asteris et al. [5] in 2016 proposed a equation using statistical regression for fundamental period. Again in 2016, Asteris et al. [4] predicted the fundamental time period using artificial neural networks using two hidden layer back propogation neural network (BPNN). The results showed that the BPNN model was accurate and reliable. In 2019, Asteris et al.[7] predicted the fundamental period using metaheuristic algorithm based neural network. They used artificial bee colony algorithm for the optimization of neural network. The results show that the ABC algorithm was a powerful tool for optimization.

The lack of dependable and robust computer programming modelling for predicting the fundamental time period of precast concrete systems can be attributed to an ' $n$ ' numbers of input parameters affecting the behaviour of the structure. The available literature depict variation $[5,6,9,11]$ in predicting the fundamental time period. As the deterministic techniques did not provide reliable estimates of output parameters as visible from the literature from last two decades, machine learning techniques such as SVM, ANN have significantly gained populairity and helped in the estimation of various output parameters. Pal and Deswal [20] used SVR on deep beams to predict the shear strength. Omran et al. [1] used SVM and GP to predict the compressive strength of concrete. Asteris et al.[7] used artificial bee colony algorithm for the optimization of neural network for predicting the fundamental period. In the present study, computer programming based on Rstudio [25] was developed for SVM and GP regression modelling to predict the $F_{T P}$ of precast building. 


\section{Support Vector Machines}

Support Vector machines (SVM) is out of the box classifier used for non linear class boundaries. SVM is an extension of support vector classifier which uses kernels to create non linear boundaries. Support vector classifier is a soft margin classifier.

Tab. 1 - Fundamental time period equation for various codes and research

\begin{tabular}{|l|l|}
\hline Fundamental time period Expression & \multicolumn{1}{|c|}{ Code/Author } \\
\hline$T=0.09 h / D^{0.5}$ & IS 1893:2016 \\
\hline$T=0.075 h^{0.75}$ & EC 8 \\
\hline$T=0.01 \mathrm{~N}$ & NBCC 2005 \\
\hline$T=0.075 \mathrm{~h}^{0.75}$ & UBC 97 \\
\hline $\mathrm{T}=0.053 \mathrm{~h}^{0.9}$ & Goel and Chopra [17] \\
\hline $\mathrm{T}=0.1 \mathrm{~h}$ & Crowley and Pinho [10] \\
\hline $\mathrm{T}=0.055 \mathrm{~h}$ & Crowley and Pinho [11] \\
\hline $\mathrm{T}=0.026 \mathrm{~h}^{0.9}$ & Guler et al. [18] \\
\hline
\end{tabular}

Vapnik in 1995 proposed $\varepsilon$ SVR by applying a $\varepsilon$ - insensitive loss function [29] which allows the problem to be solved using the concept of margin. For training data with $\mathrm{k}$ number of models defined as $\left\{x_{i}, y_{i}\right\}, i=1, \ldots \ldots, k$, where $x_{i}$ is input vector and $y_{i}$ is the target value, a linear decision function can be given by:

$$
f(x)=(w, x)+b
$$

where vector $w$ regulates the direction of a perceptive plane, while scalar $b$ regulates the offset of the perceptive plane from the origin. A miniature value of $w$ designates the flatness of Eq (3), which can be attained by reducing the Euclidean norm defined by $\|w\|^{2}$. Consequently, a problem of regression was written for optimisation.

Minimise $\frac{1}{2}\|w\|^{2}$
Subject to $\left\{\begin{array}{l}y_{i}-\left(w, x_{i}\right)-b \leq \varepsilon \\ \left(w, x_{i}\right)+b-y_{i} \leq \varepsilon\end{array}\right.$

The problem in Eq. (3) can be expressed in the form of:

$$
f(x)=\sum_{i=1}^{k}\left(\lambda^{\prime}{ }_{i}-\lambda_{i}\right)\left(x_{i} \cdot x\right)+b
$$

The approach analysed above can be expanded to allow for non-linear support regression by introducing the concept of the kernel function [30].

Support vector machines function in Eq. (5) are now written as:

$$
f(x)=\sum_{i=1}^{k}\left(\lambda^{\prime}{ }_{i}-\lambda_{i}\right) \boldsymbol{K}\left(\boldsymbol{x}_{\boldsymbol{i}} \cdot \boldsymbol{x}_{\boldsymbol{j}}\right)+b
$$

Where:

$$
K\left(x_{i} \cdot x\right) \equiv \Phi\left(x_{i}\right) \cdot \Phi\left(x_{j}\right)
$$

This relation is known as kernel function since $\boldsymbol{\Phi}(\boldsymbol{x})$ cannot be mapped in the featured space. Support vector machines function in Eq. (5) are now optimised as:

$$
f(x)=\sum_{i=1}^{k}\left(\lambda^{\prime}{ }_{i}-\lambda_{i}\right) \boldsymbol{K}\left(\boldsymbol{x}_{\boldsymbol{i}} \cdot \boldsymbol{x}\right)+b
$$

In the optimization problem, the functions used are for the computational price of working with a higher-dimensional space alternative. A reference " Nature of statistical learning theory" [30] is made for an extensive analysis of SVM and gaussian process regression has been described in detail in a journal article "gaussian process regression" [8]. 


\section{METHODOLOGY AND DATABASE}

\section{Descriptions of analytical models}

In the present research, the 288 models of the pre-cast building were analysed with different Ground floor height, material property, the number of bays and section cracking were considered (table 2). The preferred input parameters were fed in the machine learning model that include the building height, building length, building width, number of bays, number of storeys, type of sections and type of frames.
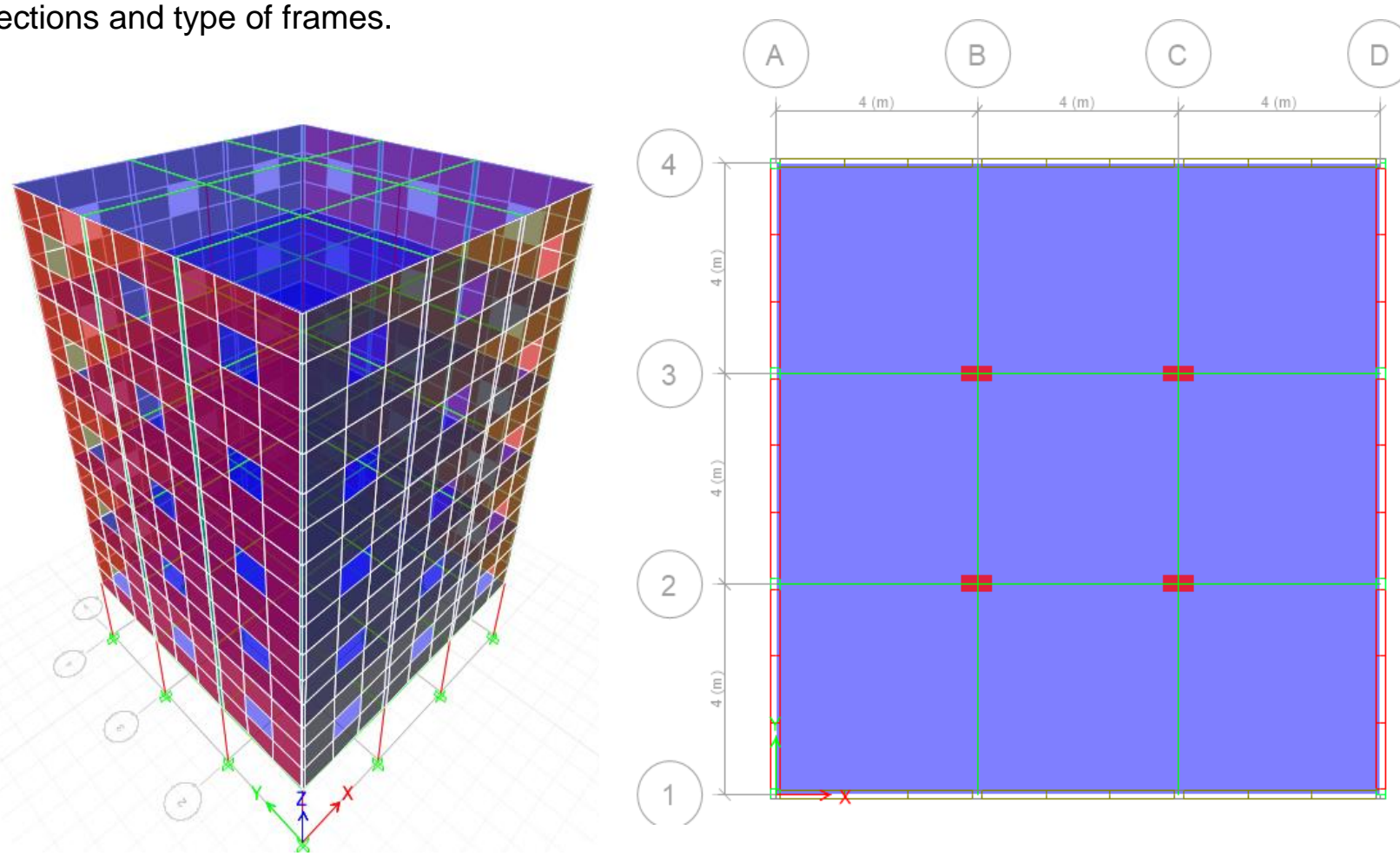

Fig. 1 - Typical Plan \& 3D view of a computer model of 6 storey building

To assess the impact of input parameters on the $F_{T P}$ of structures, 288 number of computer models were prepared. The storey height was assumed as $3 \mathrm{~m}$ for all storeys and for some models $4 \mathrm{~m}$ storey height was considered for the ground floor. The dimensions of slabs were $4 \mathrm{~m} \times 3 \mathrm{~m} \times$ $0.15 \mathrm{~m}, 4 \mathrm{~m} \times 4 \mathrm{~m} \times 0.15 \mathrm{~m}$ and cross-section of shear walls were $3 \mathrm{~m} \times 0.15 \mathrm{~m}, 4 \mathrm{~m} \times 0.15 \mathrm{~m}$ and $4 \mathrm{~m} \times 0.20 \mathrm{~m}$. The dimensions of the longitudinal and transverse beams were $450 \mathrm{~mm}$ deep and $300 \mathrm{~mm}$ wide. The size of the columns adopted was $300 \mathrm{~mm}$ wide and $600 \mathrm{~mm}$ deep. A live load of $3 \mathrm{kN} / \mathrm{m}^{2}$ and SDL of $1 \mathrm{kN} / \mathrm{m}^{2}$ was considered for analysis. M30/M40 grade concrete and also Fe 500 grade steel was utilised for design. The structure was modelled and analysed in ETABS 2015 [13] software. The ETABS software was used to analyse the burj khalifa [32]. Hence, the ETABS software is a reliable tool to be used for structural analysis and design. Seismic analysis is performed using the equivalent static and dynamic method given in IS 1893:2016. The plan and 3D modelling of the typical 6 storey structure are shown in Figure 1. To explore the outcome of each input parameters on the $F_{T P}$ of structure, a sensitivity analysis was also carried out.

\section{PERFORMANCE AND ANALYSIS OF SVM AND GPR}

Out of a total of 288 models, 67 per cent of the arbitrarily split data have been utilized in training data set using Rstudio [25]. In the current research, 180 randomly split data were used as training data set and 108 random samples were utilized as testing data. Input variable was the 


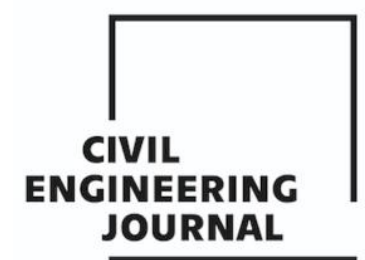

Article no. 41

THE CIVIL ENGINEERING JOURNAL 2-2021

building height, building length, building width, number of bays, number of storeys, type of sections and type of frames for both SVM and GPR. The summary of training and testing data is provided in table 3 with different analytical approaches.

In SVM and GPR, various kernel functions are used for regression. Linear kernel, RBF kernel and polynomial kernel function have positive performance as suggested by numerous studies. In the present study, three kernel functions were considered - $\operatorname{LRF}\left(K\left(x, x^{\prime}\right)=\left(x \cdot x^{\prime}\right)\right.$, $\operatorname{PLF}\left(K\left(x, x^{\prime}\right)=\left(\left(x \cdot x^{\prime}\right)+1\right)^{d}\right)$ and $\operatorname{RBF}\left(K\left(x, x^{\prime}\right)=e^{-\gamma\left|x-x^{\prime}\right|^{2}}\right)$, where $d$ and $\gamma$ are the hyper tuning parameters of $P L F$ and $R B F$ respectively. Size of error-insensitive zone $\varepsilon$ and regularisation parameter $C$ (Cost) optimum value and setting up of kernel function where required. Noise parameter is required in GPR and a trial-and-error was carried out to find the optimum value.

To select optimum values of hyper tuning parameters of SVM and GPR, a number of trails were conducted and grid search was performed. The hyper tuning parameter for SVM and GPR is given in Table 4 for which the data is working well. $L R F, P L F$ and $R B F$ with same hyper tuning parameters were used in the regression. The performance of regression approaches and their function was verified by correlation coefficient (CC) and root mean square error (RMSE).

Tab. 2 - Building input parameters

\begin{tabular}{|l|l|l|}
\hline Model & Parameters & Parameters Values \\
\hline \multirow{5}{*}{ Base Model } & No of storeys $\left(\mathrm{N}_{\mathrm{s}}\right)$ & $3 \mathrm{~m}, 6 \mathrm{~m}, 9 \mathrm{~m}, 12 \mathrm{~m}, 15 \mathrm{~m}, 18 \mathrm{~m}$ \\
\cline { 2 - 3 } & No of bays $\left(\mathrm{N}_{\mathrm{b}}\right)$ & 2 bay,3 bay,4 bay,5 bay \\
\cline { 2 - 3 } & Frame Type $\left(\mathrm{F}_{\mathrm{t}}\right)$ & Shear wall with and without opening \\
\cline { 2 - 3 } & Building Length $(\mathrm{L})$ & $8 \mathrm{~m}, 12 \mathrm{~m}, 16 \mathrm{~m}, 20 \mathrm{~m}$ \\
\cline { 2 - 3 } & Building Breadth $(\mathrm{B})$ & $\begin{array}{l}8 \mathrm{~m}, 12 \mathrm{~m}, 16 \mathrm{~m}, 20 \mathrm{~m}, 3 \mathrm{~m}, 6 \mathrm{~m}, \\
\mathrm{~m}, 12 \mathrm{~m}\end{array}$ \\
\cline { 2 - 3 } & Building Height $(\mathrm{H})$ & $9 \mathrm{~m}, 18 \mathrm{~m}, 27 \mathrm{~m}, 36 \mathrm{~m}, 45 \mathrm{~m}, 54 \mathrm{~m}$, \\
\cline { 2 - 3 } & Section Cracking $\left(\mathrm{S}_{\mathrm{c}}\right)$ & $300 \mathrm{~mm} \times 600 \mathrm{~mm}$ \\
\cline { 2 - 3 } & Column Size & $300 \mathrm{~mm} \times 450 \mathrm{~mm}$ \\
\cline { 2 - 3 } & Beam Size & $200 \mathrm{~mm}$ and $150 \mathrm{~mm}$ \\
\cline { 2 - 3 } & Shear Wall thickness & $\mathrm{M} 40$ \\
\cline { 2 - 3 } $\begin{array}{l}\text { Base Model with } \\
\text { ground floor height } \\
\text { changed }\end{array}$ & Concrete Grade & $10 \mathrm{~m}, 19 \mathrm{~m}, 28 \mathrm{~m}, 37 \mathrm{~m}, 46 \mathrm{~m}, 55 \mathrm{~m}$ \\
\hline $\begin{array}{l}\text { Base Model with } \\
\text { concrete grade } \\
\text { changed }\end{array}$ & Building Height changed & \\
\hline
\end{tabular}

Tab. 3 - Summary of the training and testing data

\begin{tabular}{|c|c|c|c|c|c|c|c|c|c|c|}
\hline \multirow{2}{*}{$\begin{array}{c}\text { Input } \\
\text { parameters }\end{array}$} & \multicolumn{5}{|c|}{ Training Data } & \multicolumn{5}{|c|}{ Testing Data } \\
\hline & Min. & Max. & Mean & Median & SDV & Min. & Max. & Mean & Median & SDV \\
\hline $\begin{array}{l}\text { No of } \\
\text { storeys }\end{array}$ & 3 & 18 & 10.8 & 12 & 5.12 & 3 & 18 & 10 & 9 & 5.12 \\
\hline No of bays & 2 & 5 & 3.26 & 3 & 1.12 & 2 & 5 & 3.89 & 4 & 0.99 \\
\hline Frame Type & 0 & 1 & 0.5 & 0.5 & 0.50 & 0 & 1 & 0.5 & 0.5 & 0.50 \\
\hline $\begin{array}{l}\text { Building } \\
\text { Length }\end{array}$ & 8 & 20 & 13.07 & 12 & 4.51 & 8 & 20 & 15.56 & 16 & 3.99 \\
\hline $\begin{array}{l}\text { Building } \\
\text { Breadth }\end{array}$ & 6 & 20 & 11.43 & 12 & 4.31 & 6 & 20 & 13.61 & 13.5 & 4.03 \\
\hline $\begin{array}{l}\text { Building } \\
\text { Height }\end{array}$ & 9 & 55 & 32.73 & 36 & 15.39 & 9 & 55 & 30.33 & 28 & 15.37 \\
\hline $\begin{array}{l}\text { Section } \\
\text { Cracking }\end{array}$ & 0 & 1 & 0.5 & 0.5 & 0.50 & 0 & 1 & 0.5 & 0.5 & 0.50 \\
\hline
\end{tabular}




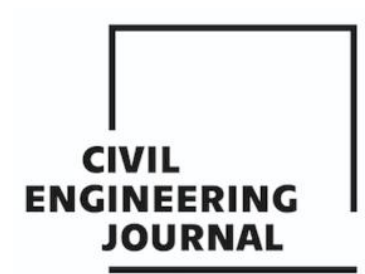

Article no. 41

THE CIVIL ENGINEERING JOURNAL 2-2021

Tab. 4 - Hyper tuning parameters used in SVM and GP

\begin{tabular}{|l|l|l|l|}
\hline $\begin{array}{l}\text { Machine } \\
\text { learning } \\
\text { Function }\end{array}$ & \multicolumn{1}{|c|}{ LRF } & \multicolumn{1}{c|}{ RBF } & \multicolumn{1}{c|}{ PLF } \\
\hline SVM & Cost $=20$ & Cost $=20$, Sigma $=0.1$ & Cost $=20$, Degree $=1$ \\
\hline GPR & Initial Noise $=1$ & Initial Noise $=1$, Sigma $=0.1$ & $\begin{array}{l}\text { Initial Noise }=1, \\
\text { Degree }=1\end{array}$ \\
\hline
\end{tabular}

\section{RESULTS AND DISCUSSION}

Figure 2 and Figure 3 provide the plot between the actual and predicted fundamental time period by $L R F, P L F$ as well as RBF according to GPR and SVM utilizing test data set. Outcomes from both SVM and GPR are within line with analysis. The optimum value of cost $=20$ for SVM and intitail noise $=1$ for GPR, a hyper-parameter was obtained by trial-and-error method. Table 5 suggests that the SVM linear kernel function perform much better compared to any kernel function in both SVM and GPR. SVM linear kernel function has a correlation coefficient of 0.9832 and RMSE of 0.0530 seconds in comparison to GPR linear kernel function which has a correlation coefficient of 0.9284 and RMSE of 0.1084 seconds. A graph between fundamental time period obtained from analysis and predicted fundamental time period by SVM and GPR versus the number of test data on the x-axis was plotted; from this plotted graph, the SVM linear kernel function predicted value is in close immediacy of fundamental time period obtained from the analysis. As linear kernel function works well with both modelling techniques, another line chart between 108 test samples and fundamental time period is plotted (Figure 4) to check whether the SVM linear kernel function works well in predicting the time period.

Tab. 5 - Evaluation of SVM and GP performance on training and testing data

\begin{tabular}{|l|l|l|l|l|}
\hline $\begin{array}{l}\text { Machine } \\
\text { Learning } \\
\text { Technique }\end{array}$ & Training Data & RMSE (Second) & Ce & RMSE (Second) \\
\cline { 2 - 5 } & CC & & & \\
\hline SVM - LRF & 0.9804 & 0.0619 & 0.9832 & 0.0530 \\
\hline SVM - PLF & 0.9577 & 0.0905 & 0.9632 & 0.0778 \\
\hline SVM - RBF & 0.9300 & 0.1148 & 0.9452 & 0.1008 \\
\hline GPR - LRF & 0.8862 & 0.1296 & 0.9284 & 0.1084 \\
\hline GPR - PLF & 0.8862 & 0.1295 & 0.9284 & 0.1084 \\
\hline GPR - RBF & 0.8708 & 0.1407 & 0.9090 & 0.1241 \\
\hline
\end{tabular}




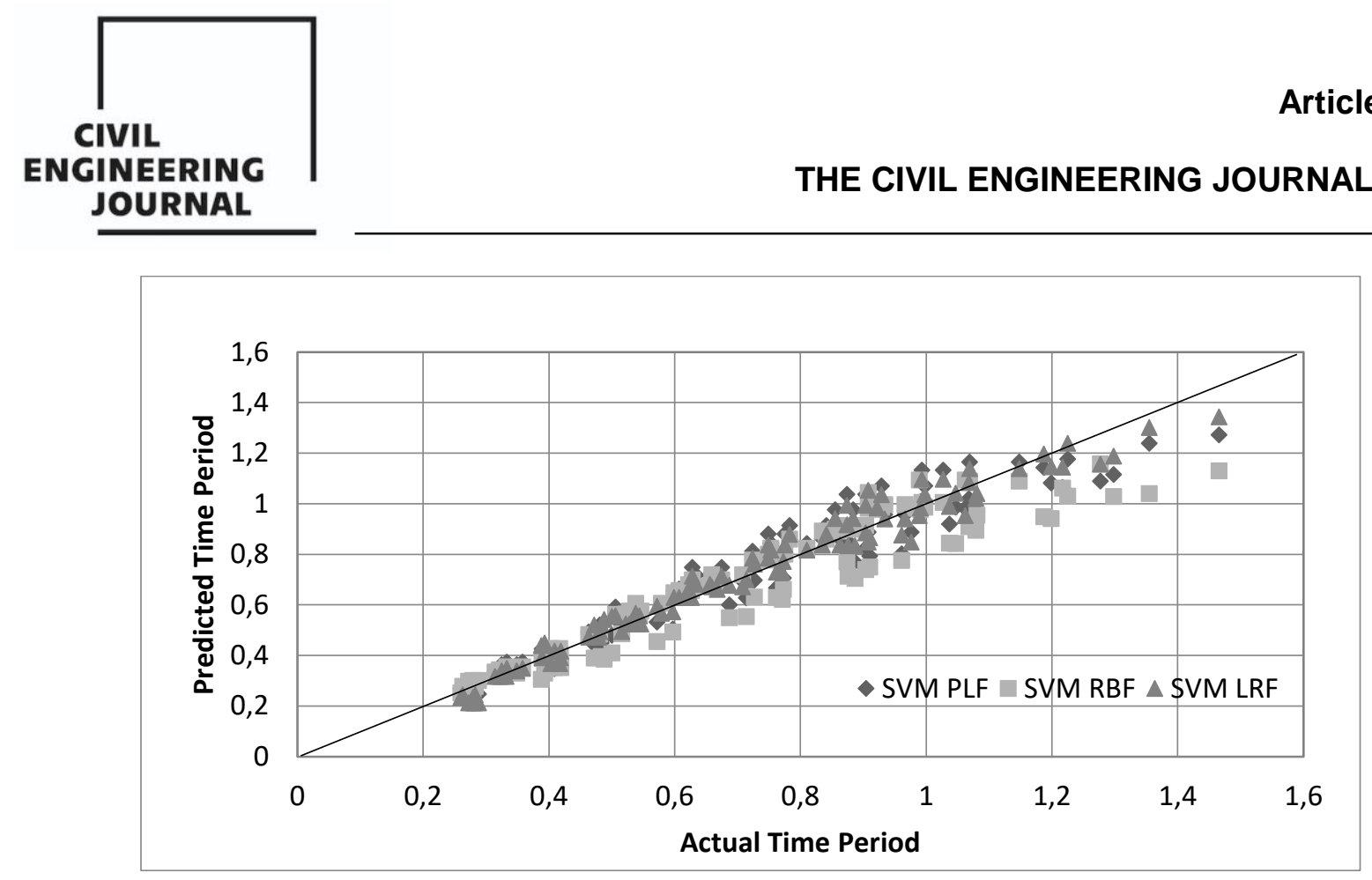

Fig. 2 - Actual time period vs predicted time period on testing data for SVM

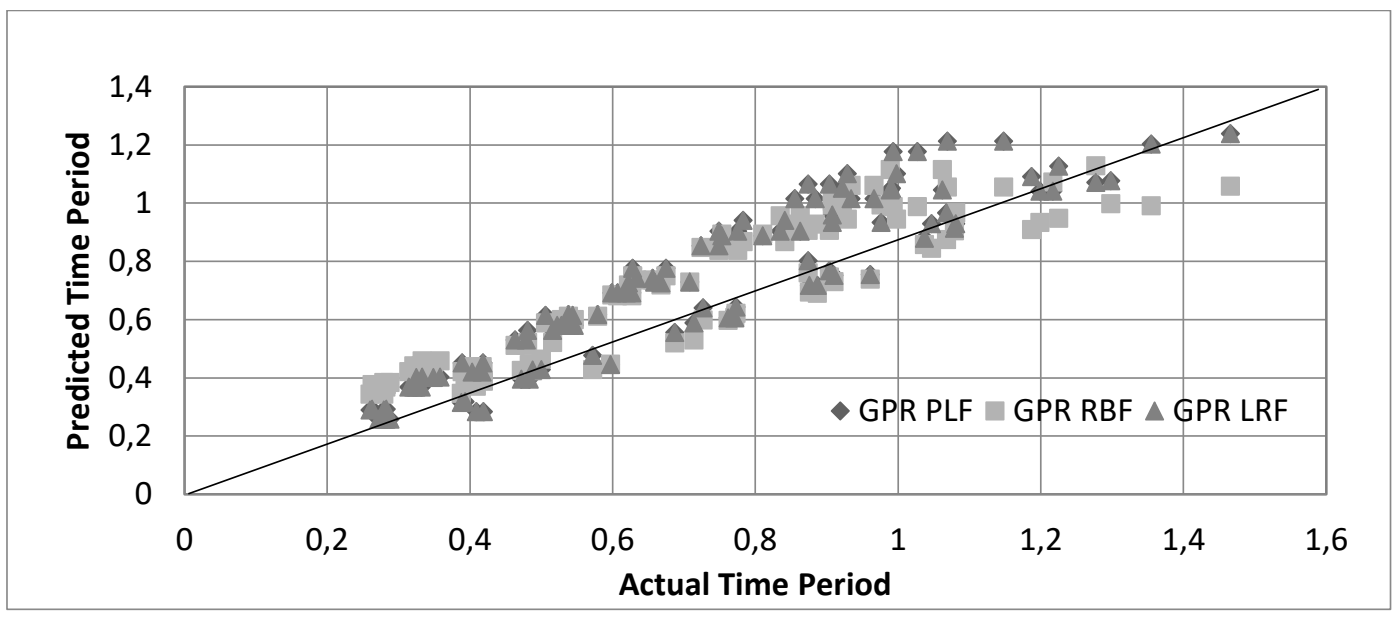

Fig. 3 - Actual time period vs predicted time period on testing data for GPR

\section{SENSITIVITY ANALYSIS}

Sensitivity analysis was performed to identify the significance of all the input variables in predicting the fundamental time period. The best kernel function is used with the training data for the analysis. SVM-LRF is used on a different set of training data by removing each input parameter:

- In first iteration all input parameters were used;

- In second iteration, frame type $\left(F_{t}\right)$ was removed,

- In third iteration, building height $(H)$ and frame type $\left(F_{t}\right)$ is removed,

- In fourth iteration, number of storeys $\left(N_{s}\right)$ and frame type $\left(F_{t}\right)$ is removed,

- In fifth iteration, number of bays $\left(N_{b}\right)$ and frame type $\left(F_{t}\right)$ is removed,

- In sixth iteration, building length $(\mathrm{L})$ and frame type $\left(\mathrm{F}_{\mathrm{t}}\right)$ is removed,

- In seventh iteration, building breadth $(B)$ and frame type $\left(F_{t}\right)$ is removed,

- In eighth iteration, section cracking $\left(S_{c}\right)$ and frame type $\left(F_{t}\right)$ is removed and 


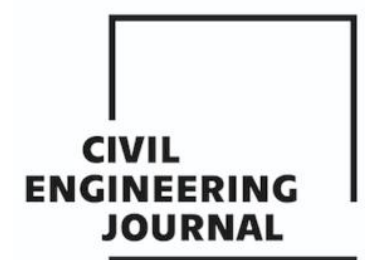

Article no. 41

THE CIVIL ENGINEERING JOURNAL 2-2021

- In the ninth iteration number of bays $\left(N_{b}\right)$, building length $(L)$ and frame type $\left(F_{t}\right)$ is removed and results were obtained and analysed in form of CC and RMSE with the test data set for all the nine iterations as shown in Table 6.

Table 6 implies that number of bays $\left(N_{b}\right)$, building length $(L)$ and frame type $\left(F_{t}\right)$ has least impact in predicting the $F_{T P}$, while building height $(H)$, number of storeys $\left(N_{s}\right)$, building breadth (B) and section cracking $\left(S_{C}\right)$ have a major role in predicting the $\mathrm{F}_{T P}$.

Tab. 6 - Sensitivity analysis

\begin{tabular}{|l|l|l|}
\hline Input Parameter & CC & RMSE (Seconds) \\
\hline$N_{s}, N_{b}, F_{t}, L, B, H, S_{c}$ & 0.9832 & 0.0530 \\
\hline$N_{s}, N_{b}, L, B, H, S_{c}$ & 0.9831 & 0.0532 \\
\hline$N_{s}, N_{b}, L, B, S_{c}$ & 0.9110 & 0.1247 \\
\hline$N_{b}, L, B, H, S_{c}$ & 0.9219 & 0.1157 \\
\hline$N_{s}, L, B, H, S_{c}$ & 0.9830 & 0.0532 \\
\hline$N_{s}, N_{b}, B, H, S_{c}$ & 0.9830 & 0.0532 \\
\hline$N_{s}, N_{b}, L, H, S_{c}$ & 0.9807 & 0.0568 \\
\hline$N_{s}, N_{b}, L, B, H$ & 0.9588 & 0.0823 \\
\hline$N_{s}, B, H, S_{c}$ & 0.9814 & 0.0557 \\
\hline
\end{tabular}

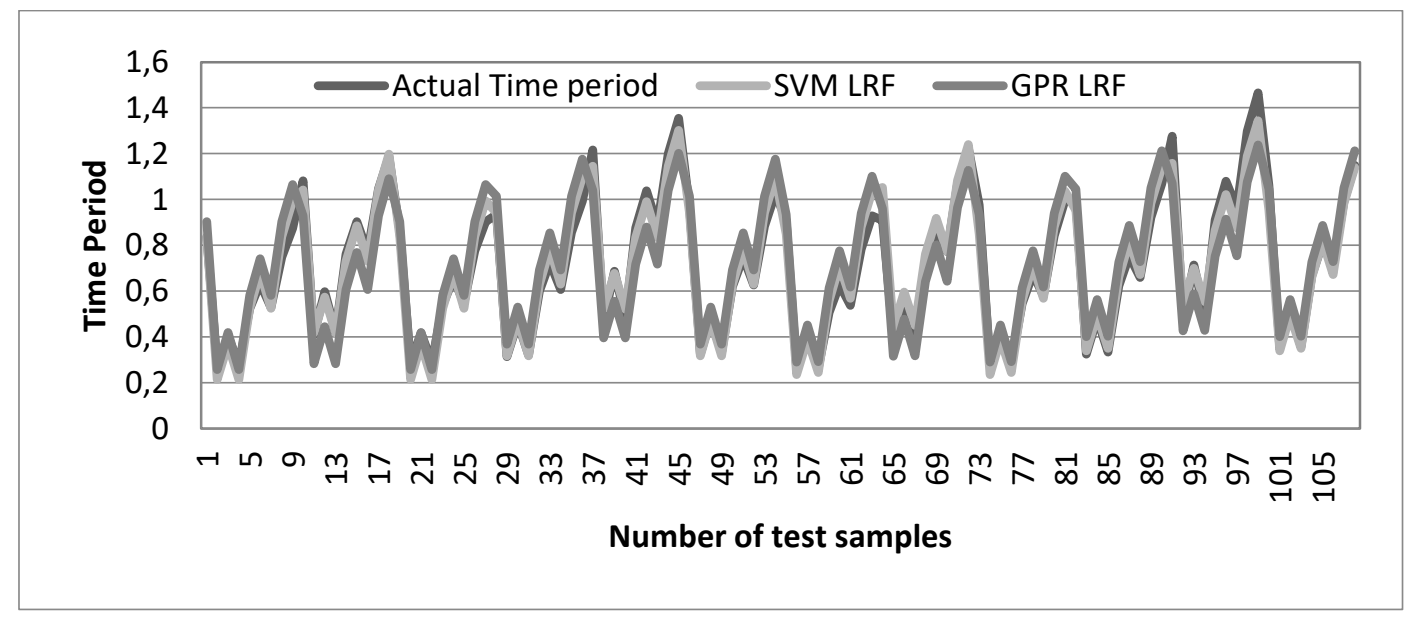

Fig. 4 - Variation in predicted values of Time period using SVM-linear and GPR-linear to the actual time period.

\section{MODEL VALIDATION}

The correlation coefficient (CC) and root mean square error (RMSE) were calculated for the machine learning technique SVM-LRF as well as for the formulae available in the literature as shown in Table 7. The lower value of RMSE indicates the more accurate predicting result and higher value of correlation coefficient indicating a heightened match in between analytical and machine learning approach values.

The advantage of SVM-LRF compared to codal equations and other literature formulae for 288 model data are given in Table 7. The highest CC value obtained is 0.9829 using SVM-LRF, whereas the lowest value obtained is 0.8609 for IS 1893. It is certainly apparent from the Table 7 that the SVM-LRF has a high correlation coefficient and low RMSE in comparison to the predicted $F_{T P}$ and the actual $F_{T P}$ (periods obtained from analysis). The CC and RMSE value of SVM-LRF model has the best fit of values than the formulae given in the literature. 
In Figure 5, the result of actual $F_{T P}$ (time period calculated from analysis) has been compared with the predicted result from SVM linear kernel function. In Figure 6, 7, 8 and 9 the result of the actual fundamental time period has been compared with the empirical formula of IS 1893:2016, NBCC 2005, EC 8 and Goel and Chopra. These outcomes demonstrate that the value of the $F_{T P}$ predicted from SVM linear kernel function offers a better fit than the values of $F_{T P}$ from empirical formulae.

Tab. 7 - Statistical results of SVM-Linear Kernel and literature formulae for all data

\begin{tabular}{|l|l|l|l|l|}
\hline Method & Mean & Std Dev & CC & $\begin{array}{l}\text { RMSE } \\
\text { (seconds) }\end{array}$ \\
\hline SVM-LRF & 0.7344 & 0.2876 & 0.9829 & 0.0561 \\
\hline IS 1893:2016 & 0.7992 & 0.4162 & 0.8609 & 0.2272 \\
\hline NBCC 2005 & 0.105 & 0.0512 & 0.8957 & 0.6847 \\
\hline EC8 & 0.9804 & 0.3743 & 0.9031 & 0.2914 \\
\hline Goel and Chopra & 1.179 & 0.5237 & 0.9053 & 0.5223 \\
\hline
\end{tabular}

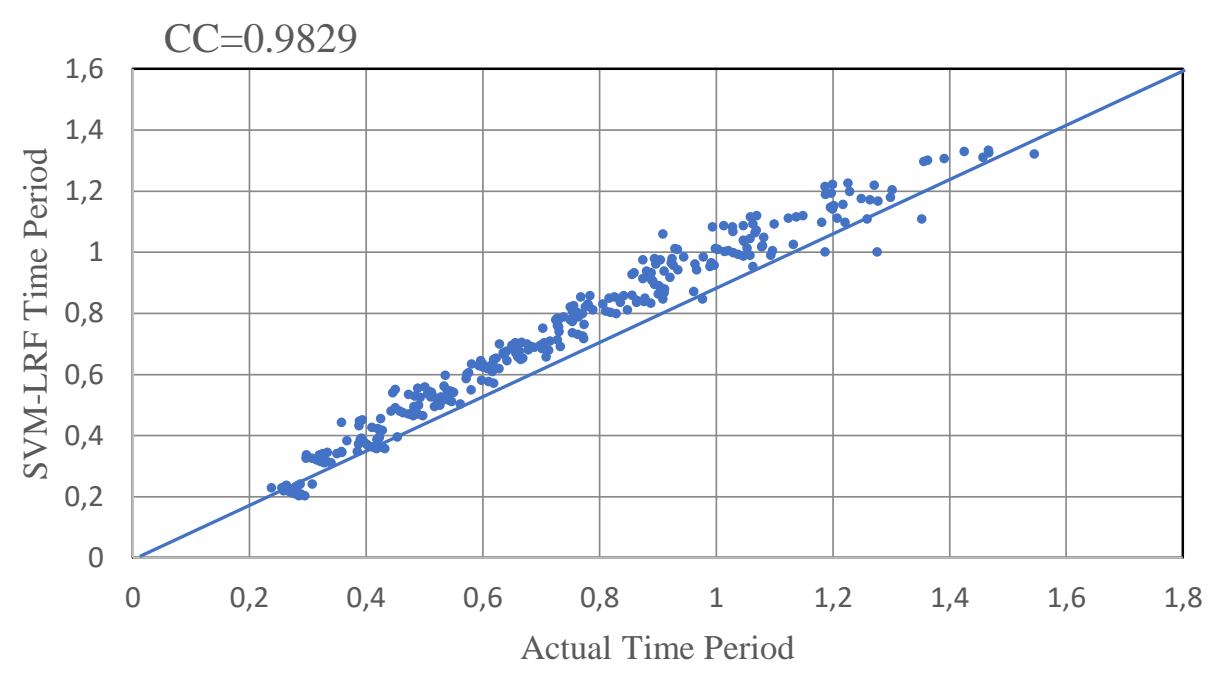

Fig. 5 - Actual Time period vs predicted time period on all data for SVM-LRF 


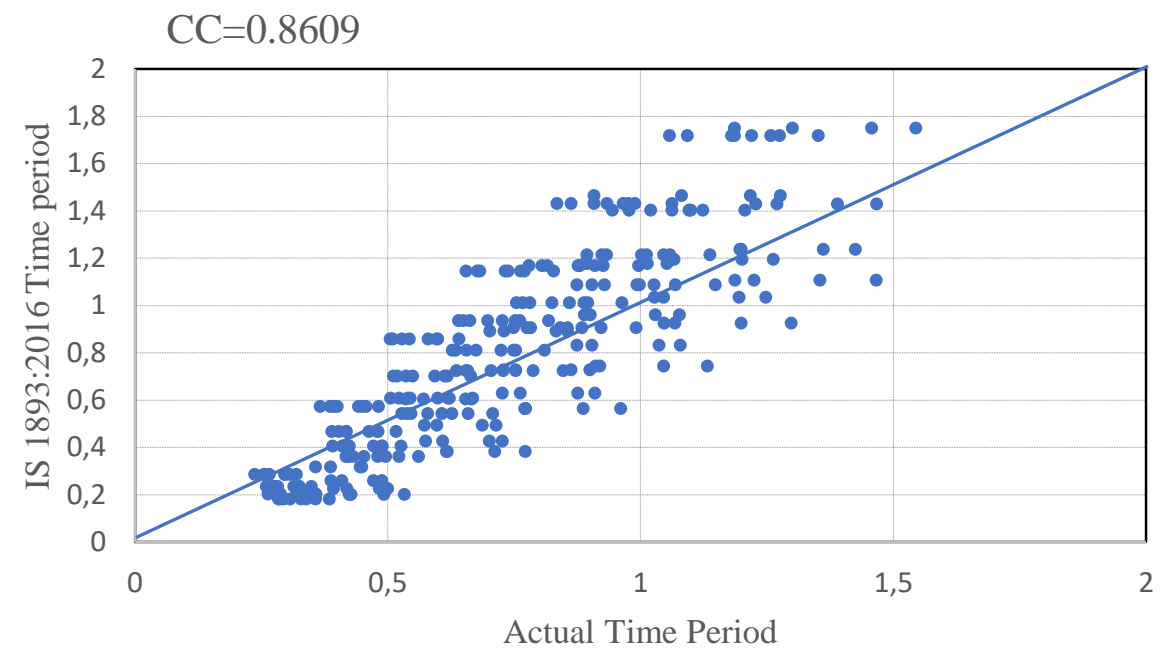

Fig. 6 - Actual Time period vs predicted time period on all data for IS 1893:2016

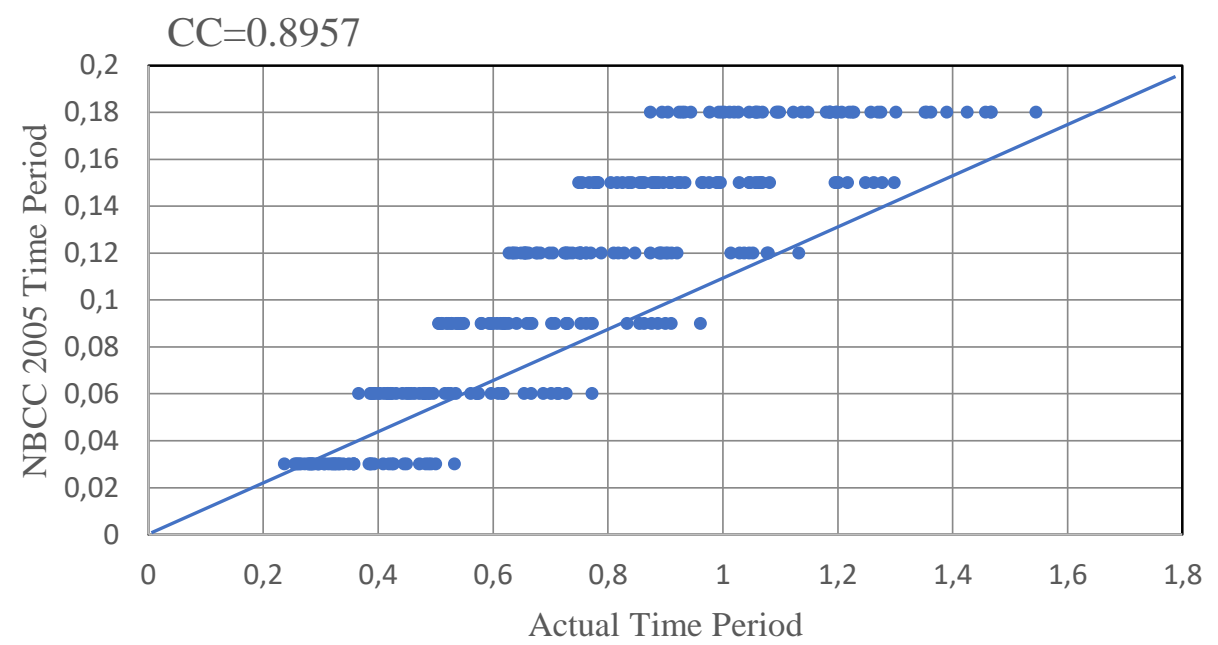

Fig. 7 - Actual Time period vs predicted time period on all data for NBCC 2005 


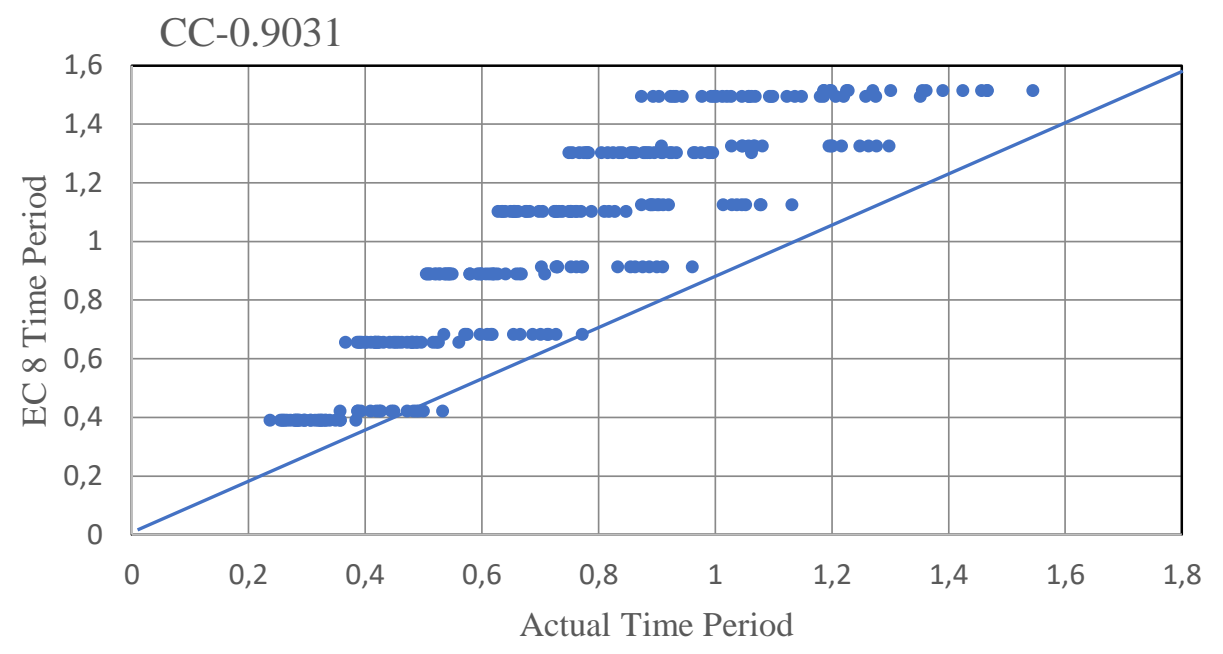

Fig. 8 - Actual Time period vs predicted time period on all data for EC 8

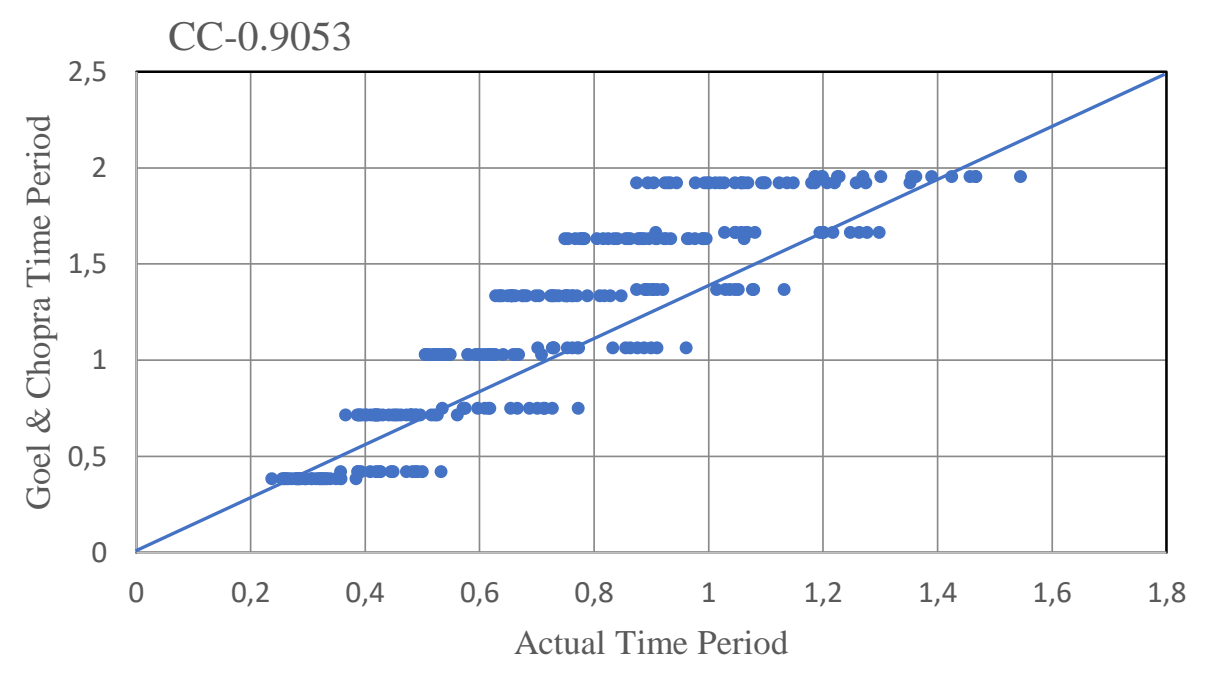

Fig 9 - Actual Time period vs predicted time period on all data for Geol \& Chopra

\section{PRACTICAL APPLICABILITY OF THE PROPOSED METHOD}

In this study, the $F_{T P}$ of precast concrete structures is predicted using computer programming. In research, practical application of proposed method is vital and important. To check the efficiency and limitation of proposed method, two models of 9 storey (total height $=27 \mathrm{~m}$ ) with slab size of $4 \mathrm{~m} \times 3 \mathrm{~m} \times 0.15 \mathrm{~m}$, beam size of $450 \mathrm{~mm}$ deep and $300 \mathrm{~mm}$ wide and column size of $300 \mathrm{~mm}$ wide and $600 \mathrm{~mm}$ deep were used. A LL of $3 \mathrm{kN} / \mathrm{m}^{2}$ and SDL of $1 \mathrm{kN} / \mathrm{m}^{2}$ was considered for analysis. M40 grade concrete and also Fe 500 grade steel was utilised for design. The $F_{T P}$ is calculated based on proposed method and IS 1893: 2016 is shown in Table 8. 


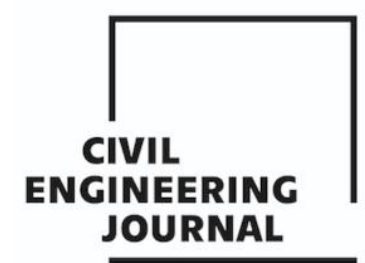

Article no. 41

THE CIVIL ENGINEERING JOURNAL 2-2021

Tab. 8 - Fundamental time period of proposed method and IS code method

\begin{tabular}{|l|l|l|}
\hline \multirow{2}{*}{ Fundamental Time Period } & Proposed Method & IS 1893:2016 \\
\cline { 2 - 3 } & 0.511 second & 0.888 second \\
\hline
\end{tabular}

Column forces and beam forces for various load combinations were calculated and compared for both the models. Column forces (Axial, shear and moment) for the proposed method was around $20 \%$ lesser than the IS code and $15 \%$ lesser in case of beam forces. The reduction in forces suggest that while designing the members using proposed method will be economical, but it has a limitation - the proposed method can be used only for buildings up to 60 metres in height.

\section{CONCLUSION}

In this study, computer programming based on Rstudio was developed for support vector machines and gaussian processes regression to predict the $F_{T P}$ of precast concrete structures. The obtained result shows that SVM works good in comparison to GPR for the data set, specifically the SVM linear kernel function provides the very best outcomes in term of CC and RMSE (CC = 0.9832 and RMSE $=0.0530$ seconds) for predicting the $F_{T P}$ of precast concrete structures. Moreover, the SVM linear kernel function appeared to fit the data better than the codal equations and other literature formulae on all data set by providing high CC and minimal RMSE. The present study also concludes that the number of bays do not have significant effect on the $F_{T P}$. There is a linear relationship between the length/ breadth with the $F_{T P}$. Cracked section is having about 13.4 $\%$ more $F_{T P}$ as compared to uncracked section. The height of the building has significant influence of the $F_{T P}$. It can also be concluded from this study that SVM is a robust and accurate modelling approach and need to be used further in structural and civil engineering problems. Present study explored the use of cost as a hyper tuning parameter to create the model, but metaheuristic algorithm can also be used for optimization of hyper tuning parameter SVM.

\section{REFERENCES}

[1] Abounia Omran, Behzad \& Chen, Q. \& Jin, Ruoyu. (2016). Comparison of Data Mining Techniques for Predicting Compressive Strength of Environmentally Friendly Concrete. Journal of Computing in Civil Engineering. 30. 04016029. 10.1061/(ASCE)CP.1943-5487.0000596.

[2] Applied Technology Council (ATC) (1978) Tentative provision for the development of seismic regulations for buildings. Report No. ATC3-06. Applied Technology Council, Redwood.

[3] Asteris PG, Repapis CC, Tsaris AK, Di Trapani F, Cavaleri L(2015) Parameters affecting the fundamental period of infilled RC frame structures. Earthq Struct 9(5):999-1028.

[4] Asteris PG, Tsaris AK, Cavaleri L, Repapis CC, Papalou A, Di Trapani F, Karypidis DF (2016) Prediction of the fundamental period of $\mathrm{RC}$ frame structures using artificial neural net-works. Comput Intell Neurosci 016:5104907

[5] Asteris PG, Repapis CC, Repapi EV, Cavaleri L (2017) Fundamental period of infilled reinforced concrete frame struct Infrastruct Eng 13(7):929-941

[6] Asteris PG, Repapis CC, Foskolos F, Fotos A, Tsaris AK(2017) Fundamental period of infilled RC frame structures with vertical irregularity. Struct Eng Mech 61(5):663-674

[7] Asteris, P.G., Nikoo, M. Artificial bee colony-based neural network for the prediction of the fundamental period of infilled frame structures. Neural Comput \& Applic 31, 4837-4847 (2019). https://doi.org/10.1007/s00521-018-03965-1

[8] Chen T, Morris J, Martin E(2007) Gaussian process regression for multivariate spectroscopic calibration, Chemometr Intell lab Syst 87(1):59-71. https://doi.org/10.1016/i. chemolab.2006.09.004

[9] Chiauzzi L, Masi A, Mucciarelli M, Cassidy JF, Kutyn K, Traber J, Ventura C, Yao F (2012) Estimate of fundamental period of reinforced concrete buildings: code provisions vs. experimental measures in Victoria and Vancouver (BC, Canada). In: Proceedings of $15^{\text {th }}$ world conference on earthquake engineering 2012 (15WCEE), Lisbon

[10] Cortes C, Vapnik VN. Support vector networks. Mach Learn 1995;20(3):273-97. 


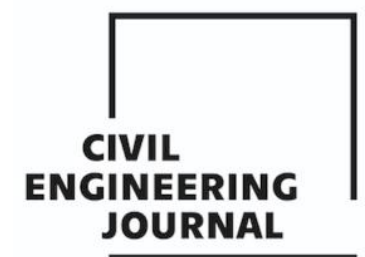

Article no. 41

THE CIVIL ENGINEERING JOURNAL 2-2021

[11] Crowley H, Pinho R (2004) Period-height relationship for existing European reinforced concrete buildings. J Earthq Eng 8(1):93-119, https://doi.org/10.1080/13632460409350522

[12] Crowley H, Pinho R (2006) Simplified equations for estimating the period of vibration of existing buildings. In: Proceedings of seismology, Geneva, 3-8 sept, Paper Number1122

[13] E-Tabs (2015)- Integrated software for structural analysis and design. Version 15.0. Berkeley. Computer \& Structures, Inc 2015.

[14] Eurocode 2: Design of concrete structured-Part 1-1: general rules and rules for buildings (2004) EN 1992-1-1, Comite Europeen de Normalisation

[15] Eurocode 8: Design of structures for earthquake resistance. Part pp 1-1998. European Standard EN Brussels

[16] European Committee for Standardization CEN (2004) Eurocode 8: design of structures for earthquake resistance -part 1: general rules, seismic actions and rules for buildings. European Standard EN 1998-1

[17] FEMA-450 (2003) NEHRP recommended provisions for seismic regulations for new buildings and other structures. Part 1: provisions. Federal Emergency Management Agency, Washington

[18] Goel RK, Chopra AK (1997) periods formulas for moment resisting frame buildings. ASCE J Struct Eng123(11):1454-1461. http://doi.org/10.1061/(ASCE)0733-9445(1997)123:11(1454)

[19] Guler K, Yuksel E, Kocak A (2008) Estimation of the fundamental period of existing RC buildings in Turkey utilizing ambient vibration records. J Earthq Eng 12(S2):140-150. http://doi.org/10.1080/13632460802013909.

[20] IS 1893 (Part 1)- 2016: Indian standard criteria for Earthquake Resistant Design of Structures, Part 1- General Provisions and Buildings (Sixth Revision), Bereau of Indian Standards, New Delhi.

[21] Pal M, Deswal S (2008) Modeling pile capacity using support vector machines and generalized regression neural network. J Geotech Geoenviron Eng 134(7):1021-1024. https://doi.org/10.1061/(ASCE)1090-0241(2008)134:7(1021)

[22] Pal M, Deswal S (2010) Modelling pile capacity using Gaussian process regression. Comput Geotech 37(7):942-947. https://doi.org/10.1061/j.compgeo.2010.07.012

[23] Pal M, Deswal S (2011) Support Vector regression based shear strength modelling of deep beams, computer and structures 89 (2011):1430-1439.

[24] Platt JC. Fast training of support vector machines using sequential minimal optimization. In: Scholkopf B, Burges C, Smola A, editors. Advances in kernels methods: support vector machines . Cambridge, MA: MIT Press:1999.

[25] RStudio Team (2015). RStudio: Integrated Development for R. RStudio, Inc., Boston, MA. http://www.rstudio.com/.

[26] Sung AH, Mukkamala S. Identifying important features for intrusion detection using support vector machines and neural networks. In: Workshop on statistical and machine learning techniques in computer intrusion detection, June 11-13, Johns Hopkins University, US: 2002.

[27] S Varadharajan, V.K. Sehgal, B. Saini, Fundamental time period of RC setback Buildings, Concrete Research Letters, vol.5, pp. 901-935, 2014b.

[28] UBC (1997). International conference of building officials (ICBO), Uniform Building Code. Whittier, California, 1997

[29] Vapnik VN. Statistical learning theory, New York: John Wiley and Sons; 1988.

[30] Vapnik VN. The nature of statistical learning theory. New York: Springer- Verlag: 1995.

[31] Witten IH, Frank E. Data mining: practical machine learning tools and techniques. $2^{\text {nd }}$ ed. San Franciso: Morgan Kaulmann; 2005.

[32] William F. Baker et al. The Challenges in Designing the World's Tallest Structure: The Burj Dubai Tower, Structures 2009: Don't Mess with Structural Engineers American Society of Civil Engineers, 2012 